Ravin, A. W. (1952). J. gen. Microbiol. 6, 211-232.

\title{
Heritable and Non-heritable Loss of Ability by Aerobacter aerogenes to Grow Adaptively on Single Carbon Sources
}

\author{
By A. W. RAVIN \\ Department of Zoology, Columbia University, Nerw York, U.S.A.
}

SUMMARY: Mutants of Aerobacter aerogenes incapable of utilizing citrate $(\mathrm{C}-$ ) were discovered in glucose cultures by a modification of the mutant-concentrating penicillin technique. These $\mathrm{C}-$ mutants utilize glucose as efficiently as does the wild-type $(\mathrm{C}+)$, despite their inability to utilize a wide range of other metabolites as carbon sources for growth, including compounds that would be oxidized if glucose were aerobically dissimilated via the Krebs cycle. The compounds that the $\mathrm{C}-$ mutants cannot utilize are citrate, $\alpha$-ketoglutarate, glutamate, succinate, fumarate, aspartate and acetate, which are all substrates to which glucose-grown $\mathrm{C}+$ cells slowly adapt. A non-genetic loss of ability to grow in media containing these substrates also occurs in glucose-grown populations under certain conditions. The $\mathbf{C}-$ mutant can revert to the prototrophic condition directly, or indirectly by first mutating to a stable state $(\mathrm{C}-\mathrm{F}+)$ in which fumarate and aspartate can be utilized whereas the other compounds cannot.

The ability of the coliform group of bacteria to utilize the so-called 'Krebs cycle compounds' is of considerable genetic, evolutionary and biochemical interest. These bacteria have long been regarded as a closely related group because of many morphological and physiological similarities (Bergey's Manual, 1948). Certain specific biochemical characters are, however, not uniformly distributed among the species in this group. Mutation is probably the process by which these differences have come about. In some strains of Escherichia coli (Bacterium coli), for example, the inability to utilize citrate, which is one of the characters used to define the species, has been reported to be affected by mutation (Parr, 1938).

Many coliform organisms which utilize Krebs cycle metabolites do so adaptively. For example Aerobacter aerogenes, after growth in a defined medium containing glucose as sole carbon source, shows adaptive utilization of acetate, succinate, fumarate and $\alpha$-ketoglutarate (Baskett \& Hinshelwood, 1949; Ajl, 1950). In the present study it was found that the ability to adapt to these compounds can undergo a stable mutation, which in no way affects the ability to utilize glucose. In addition, it was found that the ability to adapt can be lost temporarily as a result of ultraviolet irradiation or exposure to conditions which prevail in the stationary phase of certain glucose cultures.

In bacteria the relation of glucose metabolism to the dissimilation of the di- and tri-carboxylic acids remains obscure. Doubt has been raised as to whether the Krebs cycle operates in the aerobic dissimilation of glucose by coliform bacteria because of experiments in which the oxidation of various di-carboxylic acids was blocked by specific inhibitors without affecting the oxidation of glucose, e.g. succinate oxidation by malonate (Lenti, 1946; Aubel, Rosenberg \& Szulmajster, 1950); $\alpha$-ketoglutarate oxidation by arsenious 
oxide (Ajl, 1950); fumarate oxidation by cyclohexanol (Ajl, 1950). Of particular significance is the finding that fluoroacetate has no effect on the growth of $A$. aerogenes in glucose medium (Dagley, Dawes \& Morrison, 1949) although it blocks the Krebs cycle in brain and kidney tissues (Buffa, Coxon, Lièbecq \& Peters, 1949). The question cannot be considered closed, so far as the coliform bacteria are concerned, because of recent findings that aconitase, isocitric dehydrogenase, and the enzyme catalysing the synthesis of citrate from oxaloacetate and acetate, can be demonstrated in extracts prepared from Esch. coli (Novelli \& Lipmann, 1950; Dr J. R. Stern, personal communication).

Thus, enzyme investigations have been successful in isolating from Esch. coli active forms of the enzymes involved in the Krebs cycle, while inhibitor studies suggest that the Krebs cycle does not function in the aerobic dissimilation of glucose by this organism. Possibly the Krebs cycle constitutes a potentially active system in coliform organisms but does not operate during glucose dissimilation. Consistent with such a view are the results of a comparison of the physiology of the $\mathrm{C}+$ strain with a $\mathrm{C}$ - mutant (incapable of utilizing citrate) of $A$. aerogenes to be described in this paper.

\section{METHODS}

The $\mathrm{C}+$ (wild-type) strain of $A$. aerogenes used was strain no. 211 from the American Type Culture Collection. The S - and S + strains of Esch. coli K12 (strains incapable and capable of utilizing succinate, respectively) were generously furnished by DrT. C. Nelson. Stock cultures were maintained in the refrigerator on nutrient agar slopes, and were transferred every 3 months to fresh media.

Liquid cultures were prepared as follows. A small amount of the slope growth was suspended in physiological saline, and a suitable volume of this suspension was inoculated into the medium from which the experimental inocula were to be taken. When the culture was in the log phase of growth, it was placed in a sterile centrifuge tube, centrifuged, the supernatant decanted and the bacterial pellet resuspended in a volume of saline equal to that of the culture used. Measured volumes of this bacterial suspension were then inoculated into the test media. Unless otherwise indicated, $6 \mathrm{ml}$. volumes of test media contained in $16 \times 150 \mathrm{~mm}$. Pyrex test-tubes were used.

Test media. The media used included: (1) Difco nutrient broth $(0.3 \%$ meat extract $+0.5 \%$ peptone); (2) a defined medium, the inorganic salt component of which consisted of $5 \mathrm{~g} . \mathrm{NH}_{4} \mathrm{Cl} ; 1 \mathrm{~g}$. $\mathrm{NH}_{4} \mathrm{NO}_{3} ; 2 \mathrm{~g} . \mathrm{Na}_{2} \mathrm{SO}_{4} ; 0 \cdot 1 \mathrm{~g} . \mathrm{MgSO}_{4} \cdot 7 \mathrm{H}_{2} \mathrm{O}$; c. $1 \mathrm{mg} . \mathrm{CaCl}_{2} ; 3$ g. $\mathrm{K}_{2} \mathrm{HPO}_{4} ; 1$ g. $\mathrm{KH}_{2} \mathrm{PO}_{4} ; 1 \mathrm{ml}$. trace elements solution (Ryan, 1950); made up to $1 \mathrm{l}$. in distilled water. The carbon source in the defined medium was usually $0.5 \%(\mathrm{w} / \mathrm{v})$ glucose. When a different carbon source was used, its concentration was equivalent, on a carbon-for-carbon basis, with $0.0277 \mathrm{M}(0.5 \%)$ glucose. Such a concentration is referred to in the text as the standard concentration of the substrate. With the exception of D-glucose, the DL-forms of optically active carbon sources were used. The 
defined medium was adjusted with $\mathrm{NaOH}$ so that its $\mathrm{pH}$ value after sterilization

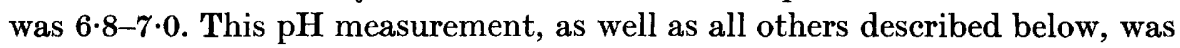
made with a Beckman glass-electrode $\mathrm{pH}$ meter. Washed agar (Ryan, 1950) was used at $1 \cdot 5-2 \cdot 0 \%(\mathrm{w} / \mathrm{v})$ for preparing solid media. Media were sterilized by autoclaving at $15 \mathrm{lb}$./sq.in. pressure for $10 \mathrm{~min}$. When solid media were used, the carbon source + agar component was sterilized separately from the mineral component. Reagent grade chemicals were used.

Cultivation. All cultures were incubated at $37^{\circ}$ in a constant-temperature room, where all measurements were made. Flask cultures, when used, were aerated in a modified shaking tank of a Warburg apparatus. Test-tube cultures were aerated by means of a roller device, which, according to Prof. F. J. Ryan (personal communication), assures optimal aeration.

Measurement of growth. Growth was measured turbidimetrically in a KlettSummerson colorimeter. The relation between number of viable bacteria $/ \mathrm{ml}$. (determined by plating) and the colorimeter readings was found to be linear over the range of 0-120 colorimeter units. At 150 units the deviation from a linear relationship was about $-5 \%$; above 150 units the deviation increased until at 350 Klett units the deviation was about -15 to $-20 \%$. Over the linear range each colorimeter unit represented about $5 \times 10^{6}$ bacteria $/ \mathrm{ml}$. In the figures illustrating this paper, the optical densities of the cultures in Klett units are plotted on a logarithmic ordinate scale.

Colony counts. The determinations of the number of cells present in a given culture that were capable of utilizing both glucose and some other substrate as carbon sources were made by appropriately diluting a culture sample and plating in two sets of defined media: (1) glucose agar (G); (2) agar containing the other substrate $(X)$ as the carbon source. After suitable incubation counts were made of plates containing from 40 to 400 colonies/plate, and an average was taken of the counts of at least two plates. Since the difference between the number of colonies on any two plates containing the same carbon source never exceeded $20 \%$, a ratio between the two averages $(\mathrm{G}: \mathrm{X})$ greater than $\mathbf{1} \cdot \mathbf{5}$, or less than $\mathbf{0} \cdot \mathbf{6 7}$, is significant.

Ultraviolet irradiation was accomplished by placing $c .5 \mathrm{ml}$. of a saline suspension of bacteria in a Petri plate and exposing the bacteria to the irradiation of a Westinghouse 'Sterilamp', which delivers approximately $85 \%$ of its radiant energy at $2537 \mathrm{~A}$.

\section{RESULTS}

Characteristics of growth of wild-type $(\mathrm{C}+)$ in defined media

Growth in media containing glucose as sole carbon source. Table 1 summarizes the effects of glucose concentration and degree of aeration of medium upon (1) growth rate (expressed as the mean generation time during the log phase of growth), (2) final level of growth, (3) limiting factor of growth.

Addition of glucose to cultures which had ceased to grow revealed that glucose exhaustion limited growth when the initial glucose concentration was $0.05 \%$. However, when the initial glucose concentration was $0.5 \%$, the addition of glucose during the stationary phase produced no growth response, for 
Table 1. Influence of glucose concentration and degree of aeration upon growth of $\mathrm{C}+($ wild-type) $\mathrm{A}$. aerogenes in defined medium

Growth of tube cultures at $37^{\circ}$ was measured turbidimetrically in a Klett-Summerson colorimeter. Rate of growth is given as the mean generation time (or time for doubling of the population during the $\log$ phase). $\mathrm{pH}$ values determined by Beckman glass electrode pH meter. Limiting factors of growth were determined by additions of glucose at end of growth and of buffer at time of inoculation (see Table 2). The G:C value given is the ratio of the count of colonies formed in glucose agar to the count of those formed in citrate agar as a result of plating an appropriately diluted sample of the culture at time indicated.

$\begin{array}{cccccccc}\text { Glucose } & \begin{array}{c}\text { Mean } \\ \text { generation } \\ \text { time (log } \\ \text { phase; }\end{array} & \text { Ratio G : C } & \begin{array}{c}\text { Final } \\ \text { gmount of } \\ \text { (Klett }\end{array} & \begin{array}{c}\text { Final pH } \\ \text { value }\end{array} & \begin{array}{c}\text { Limiting factor of } \\ \text { growth }\end{array} & \begin{array}{c}\text { Ratio G : C } \\ \text { (15 hr. }\end{array} \\ \text { stationary } \\ \text { phase) }\end{array}$

Table 2. Influence of buffer capacity of medium upon final amount of growth of $\mathbf{A}$. aerogenes

Growth of $\mathrm{C}+$ (wild-type) tube cultures containing $0.5 \%$ glucose in unaerated defined medium at $37^{\circ}$ was measured turbidimetrically. Buffer strengths in the medium are represented as the standard phosphate concentration $(1 \times)$ or two $(2 \times)$, four $(4 x)$ or eight $(8 \times)$ times this concentration.

\begin{tabular}{|c|c|c|c|c|c|c|c|c|c|c|}
\hline \multirow{2}{*}{$\begin{array}{l}\text { Buffer strength } \\
\text { in medium ... ... } \\
\text { Proportion of dibasic to } \\
\text { monobasic phosphate }\end{array}$} & \multicolumn{4}{|c|}{$1 \times$} & \multicolumn{2}{|c|}{$2 \times$} & \multicolumn{2}{|c|}{$4 \times$} & \multicolumn{2}{|c|}{$8 \times$} \\
\hline & $3: 1$ & $2: 1$ & $1: 1$ & $1: 3$ & $3: 1$ & $2: 1$ & $3: 1$ & $1: 1$ & $3: 1$ & $1: 3$ \\
\hline $\begin{array}{l}\text { Final amount of growth } \\
\text { (Klett units) }\end{array}$ & 173 & 161 & 131 & 66 & 246 & 231 & 292 & 236 & 331 & 242 \\
\hline $\begin{array}{l}\text { Initial pH value of } \\
\text { medium (after auto- } \\
\text { claving) }\end{array}$ & $6 \cdot 8$ & $6 \cdot 6$ & $6 \cdot 4$ & $6 \cdot 1$ & $6 \cdot 9$ & $6 \cdot 7$ & 6.9 & 6.5 & $6 \cdot 9$ & $6 \cdot 1$ \\
\hline
\end{tabular}

in these cultures the acid $\mathrm{pH}$ value was the limiting factor. This is shown in Table 2, which gives typical results obtained in unaerated $0.5 \%$ glucose media. An increase of the buffer concentration of the medium, without change of its initial $\mathrm{pH}$ value, greatly increased the amount of growth, while a decrease of the initial $\mathrm{pH}$ value of the medium at any buffer concentration significantly decreased this amount of growth. Phosphate was not the only buffer that could achieve this effect. The presence of citrate in unaerated $0.5 \%$ glucose media increased the final crop of the $\mathrm{C}$ - mutant strain, which, as will be seen below, cannot utilize citrate as a carbon source for growth, thus presumably leaving this substance intact to act as a buffer. Our conclusion that decreased $\mathrm{pH}$ values limited the growth of cultures of $A$. aerogenes under conditions where glucose was non-limiting, is in disagreement with that of Dagley, Dawes \& Morrison (1951). From the observation that the population density of unaerated cultures of $A$. aerogenes grown in the presence of excess glucose could be considerably increased by subsequent aeration, these authors concluded that low pH values did not adversely affect the cells. However, 
it is possible that aeration permits the resumption of growth precisely because the cells can more fully utilize some of the organic acids accumulated through glucose breakdown.

For reasons not yet understood, a serially-transferred aerated glucose culture of $A$. aerogenes occasionally changes from the faster growth rate (mean generation time $=32 \mathrm{~min}$.) typical of aerated cultures to the slower growth rate (mean generation time $=\mathbf{4 3}$ min.) characteristic of unaerated cultures. Prolonged serial transfer often results, however, in a reversion to the faster growth rate.

Adaptation of glucose-grown cells to other carbon sources. Cells grown in medium containing glucose as carbon source (to be referred to as glucosegrown cells) were able to grow in media containing any one of the following compounds as sole carbon source: glucose, glycerol, pyruvate, lactate, alanine, malate, aspartate, fumarate, succinate, acetate, $\alpha$-ketoglutarate, glutamate, citrate (but not formate). As Baskett \& Hinshelwood (1949) observed, with another strain of $A$. aerogenes, glucose-grown cells must adapt to the utilization of some of these compounds. I always observed an appreciable lag period (greater than $8 \mathrm{hr}$.) following the transfer of $c .10^{6}$ to $10^{7}$ washed, logphase, glucose-grown cells into media containing $\alpha$-ketoglutarate, succinate, fumarate, acetate, glutamate or aspartate as carbon source. A brief lag (up to $2 \mathrm{hr}$.) was observed with glucose, glycerol, pyruvate, malate or alanine. With citrate as sole carbon source, very often this brief lag was noted, but occasionally a longer lag period of 3-4 hr. was observed. Cells which have become adapted to one of the former group of compounds, as indicated by the absence of lag upon reinoculation into medium containing that compound as sole carbon source, must readapt to the utilization of that compound after transfer through glucose medium. Thus, of the substrates investigated, two classes may be distinguished: those which require a slow adaptive process before utilization by glucose-grown cells, and those which do not. As will be shown, the substrates in the former category are apparently related to each other by virtue of a particular biochemical system existing in $A$. aerogenes in which a metabolic block imposed by mutation leads to the loss of ability to utilize these compounds.

Diauxic growth in media containing glucose +another carbon source. When glucose-grown cells are inoculated into media containing a growth-limiting concentration of glucose and any one of the other carbon sources mentioned above, diauxic growth follows (see growth of wild-type in Figs. 1 and 2). As Monod (1942) showed in the case of sugar utilization by other bacterial species, the 'diauxie' observed may be interpreted on the basis that only glucose is utilized until the supply of it is exhausted, at which time the organisms then utilize the second carbon source present (see Fig. 2).

The extent of diauxic lag (the period of time intervening between the cessation of the first growth phase due to glucose exhaustion and the onset of the second growth phase due to use of the second carbon source) provides a measure of the relative magnitude of the rate of adaptation towards the second carbon source. Table 3 shows the considerable differences in the 
duration of this diauxic lag period with different secondary carbon sources. Glucose-grown cells adapt relatively slowly to use succinate, acetate or fumarate; furthermore, acetate delays the first log phase of diauxie. This confirms the inhibitory action of acetate upon glucose-utilization, as reported by Baskett \& Hinshelwood (1949).

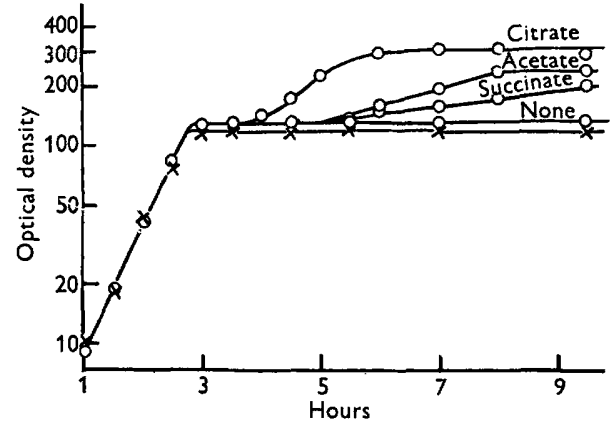

Fig. 1

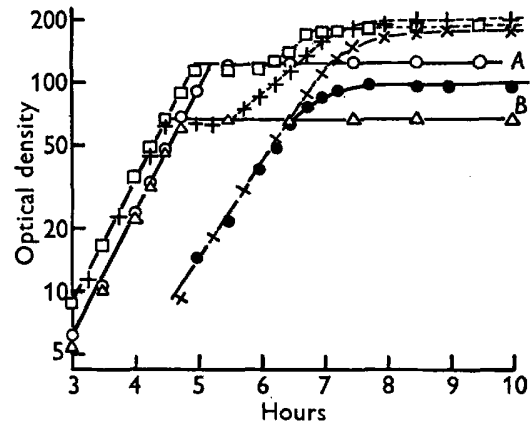

Fig. 2

Fig. 1. Growth of $\mathbf{C}+\left(-\bigcirc^{-}\right)$and $\mathbf{C}-(-\times-)$ in aerated cultures containing $0.05 \%$ glucose + one-half the standard concentration of one of the following: citrate, succinate, acetate, none. The $\mathrm{C}$ - curve shown is the same for all four types of cultures.

Fig. 2. Growth of $\mathrm{C}+$ and $\mathrm{C}-$ in aerated glucose $(\mathrm{G})$, citrate (C), and glucose + citrate cultures. $\mathbf{C}+$ in $0.05 \% \mathbf{G}\left(-\mathrm{O}_{-}\right)$, in $0.05 \% \mathbf{C}(-0-)$, in $0.1 \% \mathbf{C}(-\times-)$, in $0.025 \% \mathbf{G}$ $(-\triangle-)$, in $0.05 \% \mathrm{G}+0.05 \% \mathrm{C}(-\square-)$, and in $0.025 \% \mathrm{G}+0.1 \% \mathrm{C}(-+-)$. Curve $A$ is that obtained with $\mathrm{C}-$ in $0.05 \% \mathrm{G}$ and in $0.05 \% \mathrm{G}+0.05 \% \mathrm{C}$; curve $B$ represents $\mathrm{C}-$ in $0.025 \% \mathrm{G}$ and in $0.025 \% \mathrm{G}+0.1 \% \mathrm{C}$. (C- data were not plotted to prevent obscuring the results.) There is no growth by $\mathrm{C}-$ in $0.05 \% \mathrm{C}$ or in $0.1 \% \mathrm{C}$.

\section{Table 3. Growth of $\mathrm{C}+\mathrm{A}$. aerogenes in aerated cultures containing glucose + a second carbon source}

Aerated media containing $\mathbf{0 . 0 5} \%$ (growth-limiting) glucose + one-half the standard concentration of the indicated second carbon source were inoculated with $c .10^{7}$ glucose-grown C+ (wild-type) cells. Growth was followed turbidimetrically.

\begin{tabular}{|c|c|c|c|}
\hline $\begin{array}{l}\text { Second carbon } \\
\text { source }\end{array}$ & $\begin{array}{c}\text { First growth } \\
\text { level (utilization } \\
\text { of glucose) } \\
\text { (Klett units) }\end{array}$ & $\begin{array}{l}\text { Second growth } \\
\text { level (utilization } \\
\text { of second } \\
\text { compound) } \\
\text { (Klett units) }\end{array}$ & $\begin{array}{l}\text { Delay before second } \\
\text { growth phase began }\end{array}$ \\
\hline None & 114 & - & - \\
\hline Glycerol & 112 & 242 & $12 \mathrm{~min}$. \\
\hline Lactate & 115 & 230 & $20 \mathrm{~min}$. \\
\hline Citrate & 105 & 300 & $54 \mathrm{~min}$. \\
\hline$\alpha$-Ketoglutarate & 122 & 208 & $58 \mathrm{~min}$. \\
\hline Succinate & 122 & 312 & $1 \frac{1}{2}-2 \mathrm{hr}$. \\
\hline Fumarate & 126 & $240 *$ & $9 \mathrm{hr}$. \\
\hline Acetate & 120 & 260 & 2-3 hr. \\
\hline
\end{tabular}

* Fumarate growth was continuing slowly at termination of experiment.

$\uparrow$ Acetate caused delay in glucose-utilization of $3 \mathrm{hr}$. 


\section{Penicillin technique for screening $\mathrm{C}-$ mutants}

The $\mathrm{C}-$ mutant of $A$. aerogenes was detected by a modification of the penicillin-screening technique originally devised for the detection and isolation of auxotrophic mutants (Davis, 1948; Lederberg \& Zinder, 1948). This technique takes advantage of the fact that those cells in a culture which are actively metabolizing are more sensitive to penicillin than those which are not (Hobby, Meyer \& Chaffee, 1942; Chain \& Duthie, 1945). The experimental aim was to concentrate $\mathrm{C}$ - mutants which might be present at a low proportion in a population, by placing that population in a medium in which penicillin would selectively kill the wild-type $(\mathrm{C}+)$ cells, namely, in a medium containing citrate as sole carbon source.

The experimental procedure was as follows. Small samples from a glucose culture of $\boldsymbol{A}$. aerogenes were inoculated into test-tubes containing the selective medium, which consisted of citrate, the usual inorganic salts, and 150 to 200 units crystalline penicillin $\mathrm{G}$ sodium $/ \mathrm{ml}$. The tubes were incubated with aeration (roller device), and samples were removed between 12 and $24 \mathrm{hr}$. A sample of the source culture of the inocula and the samples from the selective medium, were diluted and plated in glucose agar and in citrate agar. Colonies were counted after 48 and $72 \mathrm{hr}$. incubation. The purpose of this plating was twofold: (1) to be able to isolate the separated clones of the cells surviving the penicillin screening; (2) to determine whether the screening procedure was efficient. The procedure could be presumed efficient if a significant discrepancy in the colony count existed between the glucose and citrate agar plates made from the penicillin-screened population and when none existed between those made from the source culture.

Since a ratio of the glucose agar count to the citrate agar count (the G:C ratio) greater than $\mathbf{1 . 5}$ is significant, the finding of such or higher ratios reveals the existence of heterogeneity in the population with respect to the ability to grow in citrate agar. It then remains to be discovered to what the heterogeneity can be attributed. To determine whether the heterogeneity could be accounted for on the basis of the proportion of stable $\mathrm{C}$ - mutants present in the population, colonies were picked from the glucose agar plates and tested for their ability to grow in defined media containing citrate as sole carbon source. This test was made in two ways : (1) by streaking directly on the surface of glucose and of citrate agar; (2) by inoculating $c .10^{6}$ to $10^{7}$ cells into liquid glucose and liquid citrate media. Those isolates characterized by ability to use glucose and inability to grow in citrate media are referred to as ' $\mathrm{C}-$ isolates'. If the heterogeneity observed in a given experiment were due solely to the proportion of $\mathrm{C}-$ mutants, then the $\mathbf{G}: \mathrm{C}$ ratio should be equivalent to the ratio of total number of glucose isolates tested to the difference between this number and the number of $\mathrm{C}$ - isolates obtained.

An investigation of various populations, differently grown or treated, provided the following results (see also Table 1). Significant G: $\mathrm{C}$ ratios were never observed in platings of: (1) glucose cultures in the log phase; (2) stationary-phase glucose cultures which had stopped growing due to exhaus- 
tion of glucose. Significant differences were consistently found in platings of: (1) unaerated, acid-limiting glucose cultures in the stationary phase; (2) logphase cultures subjected to ultraviolet irradiation; (3) populations surviving penicillin treatment. Stable C- mutants were found, however, only in penicillin-screened populations. Despite the considerable heterogeneity in irradiated populations and in unaerated stationary-phase, acid-limiting glucose cultures, no $\mathrm{C}-$ mutants were ever recovered by the method just described of testing the glucose agar isolates. Indeed, even in the case of penicillin-screened populations, it was common to find that the $\mathrm{G}: \mathrm{C}$ ratio was much greater than could be explained by the proportion of $\mathrm{C}$ - mutants recovered. Thus, in addition to genetic mutants, some apparently readily reversible modification, manifested by inability to grow in citrate agar, occurs in glucose-grown populations of $A$. aerogenes. This is extremely important technically in the penicillin-screening procedure, for it is necessary to utilize homogeneous glucose cultures as the source of populations subjected to screening. Since in populations exhibiting non-genetic heterogeneity the vast majority of the cells incapable of growing on citrate are not mutants, penicillin screening of such populations leaves the proportion of mutants so low as to render the procedure impracticable for the recovery of these mutants. For this reason, aerated log-phase glucose cultures were always used in our experiments as the source cultures for the screening of $\mathrm{C}$ - mutants.

In four different penicillin-screening experiments thirty-two independently isolated C - mutants were obtained. The results of two of these experiments are given in Tables 4 and 5 . Table 4 presents the results of an experiment in which the source culture was also subjected to a short dose of ultraviolet irradiation. The results indicate that there was homogeneity for ability to grow in citrate agar in the unirradiated population and in the irradiated population that underwent three or four divisions in aerated glucose medium. There was, however, a heterogeneity in the irradiated population that cannot be accounted for on the basis of the presence of $\mathrm{C}-$ mutants. There was heterogeneity in the populations which survived $16 \mathrm{hr}$. in the selective media that can be explained by the proportion of the $\mathrm{C}-$ mutants in those populations. This experiment was the most successful experiment performed for the recovery of $\mathrm{C}-$ mutants.

More typical results are those summarized in Table $\mathbf{5}$ from an experiment which was essentially the same as that summarized in Table 4 except that (1) no irradiation was carried out, (2) the size of the inoculum into the sterilizing medium was smaller, (3) the population surviving in the selective medium was plated before and after washing with saline. This experiment revealed the typical finding with populations which survive penicillin treatment, namely, that most of the heterogeneity is due to cells whose inability to grow on citrate is not an inherited and stable character. Nevertheless, some $\mathbf{C}$ - isolates were obtained even where non-genetic heterogeneity existed in penicillin-treated populations. It is also clear that washing the surviving populations had no effect on the total viable count or on the $\mathrm{G}$ :C ratio. 
Table 4. Detection and isolation of $\mathrm{C}-$ mutants of $\mathrm{A}$, aerogenes (Exp. 1)

The source culture was an aerated glucose $(0.05 \%)$ culture in the log phase. Viable counts of a diluted sample of the source culture were determined on glucose agar and on citrate agar at time of removal of inocula for various treatments. Viable counts of diluted samples of variously treated populations were similarly obtained by plating on glucose and citrate agar. The selective medium consisted of the salts of the defined medium + the standard concentration of citrate +200 units crystalline penicillin $\mathbf{G}$ sodium $/ \mathrm{ml}$.

\begin{tabular}{|c|c|c|c|c|c|}
\hline \multirow[b]{2}{*}{ Population tested } & \multicolumn{2}{|c|}{ Counts on } & \multirow[b]{2}{*}{$\begin{array}{l}\text { Ratio } \\
\text { G : C }\end{array}$} & \multirow[b]{2}{*}{$\begin{array}{l}\text { No. of glucose } \\
\text { colonies tested }\end{array}$} & \multirow[b]{2}{*}{$\begin{array}{c}\text { No. of } \\
\text { C-mutants }\end{array}$} \\
\hline & $\begin{array}{c}\text { Glucose } \\
\text { agar } \\
(\mathbf{G}) \\
\text { (Bacteria/m }\end{array}$ & $\begin{array}{l}\text { Citrate } \\
\text { agar } \\
\text { (C) } \\
\text { l. sample) }\end{array}$ & & & \\
\hline $\begin{array}{l}\text { Unirradiated source } \\
\text { culture (U) }\end{array}$ & $1.42 \times 10^{8}$ & $1.30 \times 10^{8}$ & $1 \cdot 1$ & 20 & $\mathbf{0}$ \\
\hline $\begin{array}{l}\text { Irradiated source } \\
\text { culture (I) }\end{array}$ & $1.81 \times 10^{7}$ & $0.60 \times 10^{7}$ & $3 \cdot 0$ & 20 & $\mathbf{0}$ \\
\hline $\begin{array}{l}\text { Irradiated culture after } \\
\text { aeration in glucose } \\
\text { medium (IG) } \\
\text { U population in selective } \\
\text { medium at: }\end{array}$ & $1.82 \times 10^{8}$ & $1 \cdot 61 \times 10^{8}$ & $1 \cdot 1$ & 20 & $\mathbf{0}$ \\
\hline Zero time (0 hr.) & $23 \cdot 3 \times 10^{5}$ & $21 \cdot 3 \times 10^{5}$ & $1 \cdot 1$ & - & - \\
\hline $\begin{array}{l}16 \mathrm{hr} \text {. } \\
\text { IG population in selective } \\
\text { medium at: }\end{array}$ & $12.8 \times 10^{3}$ & $4.0 \times 10^{3}$ & $3 \cdot 2$ & 14 & 13 \\
\hline Zero time $(0 \mathrm{hr})$. & $29.8 \times 10^{5}$ & $26.4 \times 10^{5}$ & $1 \cdot 1$ & - & - \\
\hline $16 \mathrm{hr}$. & $20.5 \times 10^{3}$ & $2.8 \times 10^{3}$ & $7 \cdot 3$ & 14 & 12 \\
\hline
\end{tabular}

Table 5. Detection and isolation of $\mathrm{C}-$ mutants of $\mathrm{A}$. aerogenes (Exp. 2)

The source of inoculum was an aerated glucose $(0.05 \%)$ culture in the log phase. Viable counts of a diluted sample of the source culture were determined on glucose agar and on citrate agar at time of removal of inoculum for selective medium. Viable counts of diluted samples of selective medium were similarly determined immediately after inoculation and at $19 \mathrm{hr}$. after inoculation. The expected $\mathrm{C}$-proportion was calculated as the proportion of cells forming colonies on glucose agar which did not form colonies on citrate agar.

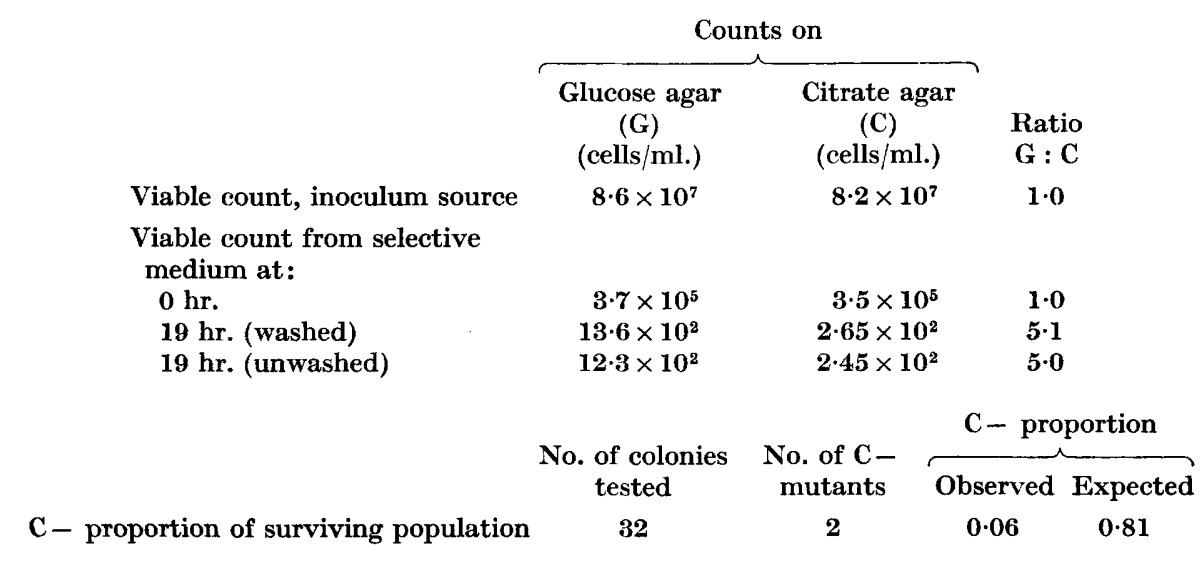




\section{Stability of wild-type and mutant strains}

All the physiological experiments described below were performed with two of the $\mathrm{C}-$ isolates obtained from screening the unirradiated population indicated in Table 4. These two $\mathrm{C}-$ isolates, as well as the wild-type strain of $A$. aerogenes, were maintained for 200-300 generations in aerated nutrient broth and in aerated glucose cultures $(25 \mathrm{ml}$. of medium contained in $125 \mathrm{ml}$. Erlenmeyer flasks). Serial transfer was effected by diluting a sample of a previous culture which had stopped growing, so that $c .50$ cells were transferred into a flask of sterile medium. Approximately twenty-six generations of growth took place in each flask culture. At the beginning and at the end of the serial transfer, $c .10^{6}$ cells were tested for growth in defined medium containing citrate as sole carbon source. The $\mathrm{C}+$ (wild-type) strain retained its ability to utilize citrate as the sole carbon source and the $\mathrm{C}$ - strain remained unable to utilize citrate. This result was obtained whether aerated nutrient broth or aerated glucose was employed as the medium for serial transfer. One may conclude, therefore, that the citrate-utilizing character in the $\mathrm{C}+$ (wild-type) strain is a stable inherited character, as is the inability of the $\mathrm{C}-$ mutant to utilize citrate. We are justified, therefore, in considering the $\mathrm{C}-$ strain as a stable genetic mutant of $A$. aerogenes.

\section{Non-genetic loss of ability to grow in media containing certain carbon sources}

Populations of $A$. aerogenes which have stopped growing in unaerated $0.5 \%$ glucose cultures due to the development of a low $\mathrm{pH}$ value become heterogeneous with respect to ability to grow in citrate agar. The percentage of cells unable to grow in citrate agar is a function of the time they are exposed to the growth-limiting conditions in the stationary phase (Fig. 3). The rate of increase of these cells is exponential; the percentage of cells which cannot grow in citrate agar doubles approximately every $5 \mathrm{hr}$. An interpretation of the kinetics of this phenomenon is presented elsewhere (Ravin \& Norman, 1952).

In a certain experiment a heterogeneous culture, after $20 \mathrm{hr}$. in the stationary phase, contained $c .12$ times more cells that would grow in glucose than would grow in citrate agar. Yet when forty-eight of the glucose colonies were tested for citrate-utilization (as described in the section on mutant screening), each one grew as well in defined citrate media as did the control colonies isolated from the citrate agar plates. Identical results were obtained in several similar experiments. Clearly the loss of ability to grow in citrate medium which is induced in unaerated stationary-phase $0.5 \%$ glucose cultures is extremely unstable.

The following experiment was performed to rule out back-mutation and selection of $\mathbf{C}+$ progeny as the basis of this instability. A heterogeneous glucose culture was washed and samples were removed, before and after washing, for plating and for inoculation into tubes of defined medium. These tubes, which either lacked a carbon source or contained $0.5 \%$ glucose, were 
incubated without aeration. Samples from the tubes were plated after $1 \frac{1}{2}$ and $4 \mathrm{hr}$. Some of the platings were made on succinate and lactate agars as well as on the usual glucose and citrate agars. The results are given in Table 6. Homogeneity was fully restored in $4 \mathrm{hr}$. in the unwashed population as well as in the washed population provided with a carbon source.

\section{Table 6. The restoration of homogeneity in a heterogeneous glucose culture of $\mathbf{A}$. aerogenes}

Sample populations from an unaerated stationary-phase glucose $(0.05 \%)$ culture were inoculated into defined media under the conditions shown, and the restoration of homogeneity to the populations was followed by platings on glucose, citrate, succinate and lactate agars.

\begin{tabular}{|c|c|c|c|c|c|c|}
\hline \multirow{2}{*}{ Inoculum } & \multirow[b]{2}{*}{ Medium } & \multirow[b]{2}{*}{$\begin{array}{l}\text { Time } \\
\text { (hr.) }\end{array}$} & \multicolumn{4}{|c|}{ Colony counts in } \\
\hline & & & $\begin{array}{l}\text { Glucose } \\
\text { agar } \\
\text { (Ba }\end{array}$ & $\begin{array}{c}\text { Citrate } \\
\text { agar } \\
\text { teria } \times 1\end{array}$ & $\begin{array}{l}\text { Succinate } \\
\text { agar } \\
0^{5} / \mathrm{ml} \text {. sam }\end{array}$ & $\begin{array}{l}\text { Lactate } \\
\text { agar } \\
\text { ple) }\end{array}$ \\
\hline $\begin{array}{l}\text { Unwashed population } \\
\text { from source culture }\end{array}$ & Salts minus glucose & $\begin{array}{l}0 \\
1 \cdot 5 \\
4\end{array}$ & $\begin{array}{r}74 \cdot 3 \\
151 \cdot 0 \\
225 \cdot 0\end{array}$ & $\begin{array}{r}10 \cdot 6 \\
107 \cdot 0 \\
190 \cdot 0\end{array}$ & $\begin{array}{l}0.17 \\
-{ }_{156 \cdot 0}\end{array}$ & $\begin{array}{c}67 \cdot 7 \\
-- \\
229 \cdot 0\end{array}$ \\
\hline $\begin{array}{l}\text { Washed population } \\
\text { from source culture }\end{array}$ & Salts minus glucose & $\begin{array}{l}0 \\
1 \cdot 5 \\
4\end{array}$ & $\begin{array}{l}51 \cdot 1 \\
84 \cdot 0 \\
75 \cdot 0\end{array}$ & $\begin{array}{r}9 \cdot 7 \\
52 \cdot 0 \\
39 \cdot 0\end{array}$ & $\begin{array}{l}0 \cdot 13 \\
9 \cdot 0\end{array}$ & $\frac{54 \cdot 4}{71 \cdot 0}$ \\
\hline $\begin{array}{l}\text { Washed population } \\
\text { from source culture }\end{array}$ & Salts plus glucose & $\begin{array}{l}0 \\
1 \cdot 5 \\
4\end{array}$ & $\begin{array}{r}51 \cdot 1 \\
88 \cdot 0 \\
160 \cdot 0\end{array}$ & $\begin{array}{r}9 \cdot 7 \\
60 \cdot 0 \\
180 \cdot 0\end{array}$ & $\frac{0 \cdot 13}{173 \cdot 0}$ & $\frac{54 \cdot 4}{-}$ \\
\hline
\end{tabular}

Since the mean generation time of $A$. aerogenes in unaerated glucose media is $4.3 \mathrm{~min}$., at most only two generations can take place in $1 \frac{1}{2} \mathrm{hr}$. and about five generations in $4 \mathrm{hr}$. If the cells unable to grow in citrate or in succinate media were stable mutants, with a reversion rate, say, of $10^{-4}$ to $10^{-6}$ /generation/cell, then a selection hypothesis would have to explain the increases in the numbers of $\mathbf{C}+$ and $\mathbf{S}+$ cells as being due to the growth of these cells. However, such growth increases as were actually observed, namely, a tenfold increase in $1 \frac{1}{2} \mathrm{hr}$. of the number of cells able to grow in citrate and a 900-fold increase within the same time of the number of cells able to grow in succinate, are patently impossible. One can only conceive of the restoration of homogeneity as a process whereby those cells initially incapable of growing on citrate (or succinate) regain this ability.

In the experiment summarized in Table 6 it may be seen that cultures heterogeneous for ability to grow in citrate are also heterogeneous for ability to grow in succinate, but homogeneous for ability to grow in lactate. Subsequent experiments, involving the plating of heterogeneous glucose cultures in media containing different carbon sources, revealed that the non-genetic modification affects ability to grow in media containing as sole carbon sources those substrates to which $\mathrm{C}+$ (wild-type) slowly adapts. The ability to grow in glycerol, lactate, pyruvate or malate media is unaffected, whereas the ability to grow in citrate, succinate, $\alpha$-ketoglutarate, acetate or fumarate media is lost. 


\section{Comparison of growth of $\mathrm{C}+$ and of $\mathrm{C}-$ strains in nutrient broth}

In studies of the comparative physiology of the wild-type and mutant strains of $\boldsymbol{A}$. aerogenes, all experiments were performed at least twice; in the original experiment one $\mathrm{C}$ - isolate was used, and in the repeat the second isolate was generally used. Identical results were always obtained.

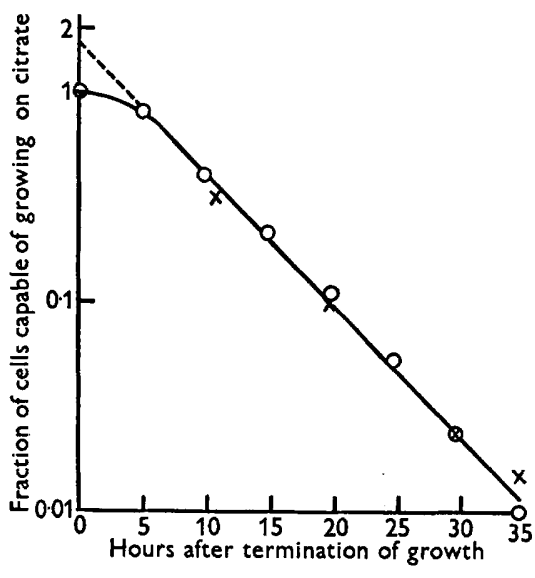

Fig. 3

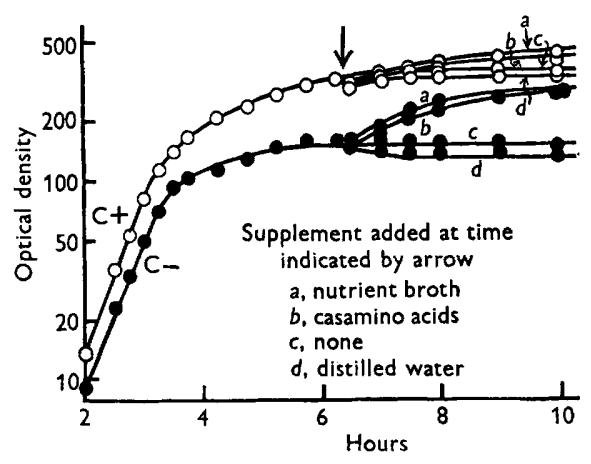

Fig. 4

Fig. 3. Fraction of population (in growth-terminated unaerated glucose culture) capable of growing in citrate agar; as a function of time after termination of growth. Values plotted are calculated from colony-count data as the fraction of cells capable of growing in glucose agar which are also capable of growing in citrate agar. $x=$ data from a single experiment; $O=$ averaged results from five different experiments. The ordinate scale is logarithmic.

Fig. 4. Growth of $\mathrm{C}+\left(-\mathrm{O}_{-}^{-}\right)$and $\left.\mathrm{C}-(-)^{-}\right)$in aerated nutrient broth cultures. Cultures received supplement at time indicated by arrow.

Fig. 4 shows the results of an experiment in which the growth of $\mathrm{C}+$ and of $\mathrm{C}-$ was followed in aerated nutrient broth cultures. Approximately $10^{7}$ cells from glucose-grown populations were inoculated in the usual way into each of four tubes containing $6 \mathrm{ml}$. nutrient broth. After growth had stopped, $1.0 \mathrm{ml}$. of sterile $6 \times$ concentrated nutrient broth was added to one tube, $1.0 \mathrm{ml}$. of sterile $12 \%(\mathrm{w} / \mathrm{v}$ ) Casamino acids (Difco) was added to another, and $1.0 \mathrm{ml}$. of sterile distilled water was added to a third tube which was used as a control for the effect of dilution. The fourth tube received no addition of any kind.

The following facts can be noted:

(1) $\mathrm{C}+$ and $\mathrm{C}-$ grow at the same rate during the log phase (generation time 28-30 min.); (2) $\mathrm{C}+$ attains a higher level of growth (c. 350 Klett units) than does $\mathrm{C}-$ (c. 150 Klett units); (3) the growth of both $\mathrm{C}+$ and $\mathrm{C}-$ can be increased by the addition of substances present in nutrient broth, and is therefore apparently limited by the exhaustion of these substances. These substances are replaceable by the amino-acids in the acid digest of casein (Casamino acids). The hypothesis is proposed that there are substances in 
nutrient broth which can be utilized by $\mathrm{C}+$ but not by $\mathrm{C}-$. The amount of citric acid in nutrient broth could hardly account for the difference in the amounts of growth of $\mathrm{C}+$ and $\mathrm{C}-$. Therefore, if this hypothesis is correct, $\mathrm{C}-$ must also be incapable of utilizing certain compounds, other than citrate, which are present in nutrient broth.

\section{Metabolites utilized by $\mathrm{C}+$ and $\mathrm{C}-$ strains}

Loss of ability of $\mathrm{C}-$ strain to utilize substrates to which $\mathrm{C}+$ slowly adapts. To test the hypothesis suggested by the comparison of the growth of $\mathrm{C}+$ and $\mathrm{C}$ - in nutrient broth, we examined the ability of $\mathrm{C}$ - to utilize the carbon sources previously investigated with wild-type $\mathrm{C}+$. The tests were made in two ways: (1) by streaking $c .10^{8}$ to $10^{9}$ cells from nutrient agar slopes on to the surface of defined media solidified by washed agar; (2) by inoculating c. $10^{6}$ to $10^{7}$ glucose-grown cells into aerated tubes of liquid-defined media. Any given test medium contained only one carbon source (except the agar in solid media), namely, the compound the utilization of which was being investigated.

In the liquid cultures, growth of the $\mathrm{C}+$ (wild-type) strain, used as control, was like that described in the section on 'Adaptation' above. But the $\mathrm{C}-$ mutant did not grow at all in cultures containing citrate, $\alpha$-ketoglutarate, succinate, fumarate, acetate, glutamate or aspartate as sole carbon source. In liquid media containing glucose, glycerol, malate, pyruvate, lactate or alanine, $\mathrm{C}-$ grew with the same very brief lag period shown by the $\mathrm{C}+$ wild-type.

The results obtained by the agar streak technique corroborated those obtained with the aerated tube cultures. With the surface streaks, however, lag was indicated by the length of time before appreciable surface growth was visible over the light background smear of cells initially spread on the surface. Even where the lag period was long, as with fumarate agar, growth of $\mathrm{C}+$ always appeared homogeneously over the surface of the agar. The entire background smear developed continuously into the final surface growth, and papillations never occurred.

The appearance of the $\mathrm{C}$ - mutant streak on fumarate agar was different. Within the streaked area, several ( 8 to 10 ) papillae appeared at about 5 days of incubation; these papillae grew gradually into large surface colonies which could be isolated and tested. It was presumed that the papillae were clones developing from mutants present in the original heavy streak inoculum, which mutants had regained the ability to utilize fumarate. Occasionally in these experiments one or two such papillae appeared on the surfaces of citrate, $\alpha$-ketoglutarate or succinate agars which had been heavily streaked with $\mathrm{C}-$ cells (see below).

A summary of the results of these substrate-utilization tests is given in Table 7, which shows that a wide variety of substrates utilizable as carbon sources for the growth of the wild-type $(\mathrm{C}+)$ were not utilized by the $\mathrm{C}-$ mutant. Furthermore, the class of compounds not utilized by $\mathrm{C}-$ corresponds to the class of compounds not utilized by glucose-grown $\mathrm{C}+$ cells until after 
an appreciable lag period. The smaller amount of growth by $\mathrm{C}-$ in nutrient broth is now explainable on the ground that two carbon sources present in nutrient broth in large quantities, aspartate and glutamate, cannot be utilized by $\mathrm{C}-$ for growth. It is also conceivable that other amino-acids present in nutrient broth cannot be utilized by $\mathrm{C}$ - because, in order to be utilized, they must be metabolized via a pathway involving some of the compounds not utilizable by $\mathrm{C}$ - .

\section{Table 7. Substrates utilized by $\mathrm{C}+$ and by $\mathrm{C}-$ strains of $\mathrm{A}$. aerogenes}

Utilization of substrate was determined by presence or absence of growth in liquid cultures in defined medium containing indicated substrate as sole carbon source and by streak cultures on surfaces of similar media solidified with washed agar. Of the compounds listed the ones in the right-hand column are those to which $\mathrm{C}+$ (wild-type) cells slowly adapt after being previously grown on glucose.

Substrates utilized by
$\mathrm{C}+$ and by $\mathrm{C}-$ strains
Glucose
Glycerol
Pyruvate
Lactate
Alanine
Malate

\author{
Substrates utilized only by \\ C+ strain \\ Fumarate \\ Aspartate \\ Succinate \\ Acetate \\ Glutamate \\ $\alpha$-Ketoglutarate \\ Citrate
}

Behaviour of $\mathrm{C}-$ mutant with respect to fumarate and malate. To verify the behaviour of the $\mathrm{C}$ - mutant with respect to malate and fumarate, two other independent methods were employed. First of all the S- strain of Esch. coli K12 (Nelson, 1949) was used as an assay organism. Fumarate and malate agar were prepared in the usual way and different sectors of the agar were streaked with $A$. aerogenes $\mathrm{C}+$ (wild-type), with $A$. aerogenes $\mathrm{C}-$ mutant, with $E s c h$. coli $\mathrm{S}+$ or with $E s c h$. coli $\mathrm{S}-$. As Nelson has previously reported, Esch. coli $\mathbf{S}+$ is $\mathbf{F}+\mathbf{M}+$ (fumarate- and malate-utilizing), whereas the $\mathbf{S}-$ strain is $\mathbf{F}-\mathbf{M}-$. On the same test agars, $A$. aerogenes $\mathbf{C}+$ was $\mathbf{F}+\mathbf{M}+$, whereas $\mathbf{C}$ - was $\mathbf{F}-\mathbf{M}+$. Two sets of media were prepared containing the standard concentration of malate as sole carbon source; one set was sterilized by autoclaving and the other by filtration through a sintered glass filter. The growth of $\mathrm{C}+$ and of $\mathrm{C}-$ in aerated tubes of the two media was followed turbidimetrically. No differences were observed in any of the growth characteristics (rates, final amounts, etc.) of $\mathrm{C}+$ or of $\mathrm{C}$ - in either type of medium. There seems little reason to doubt, therefore, that the $\mathrm{C}$ - mutant is truly capable of utilizing malate while incapable of utilizing fumarate.

\section{Comparison of growth of $\mathrm{C}+$ and $\mathrm{C}-$ strains in glucose media}

Growth in aerated glucose cultures. A comparison was made between the growth of the $\mathrm{C}+$ and $\mathrm{C}$ - strains in media containing glucose as sole carbon source. Fig. 5 gives the results of one of numerous similar experiments in which glucose-grown inocula were aerated in tubes containing glucose $(0.5$ or $0.05 \%$ ) medium. It is clear that in cultures where exhaustion of glucose limited growth no difference could be detected between either the rates or the 
final amounts of growth of $\mathrm{C}+$ or $\mathrm{C}-$. In cultures where acid $\mathrm{pH}$ values caused growth to stop, the rates of growth of $\mathrm{C}+$ and $\mathrm{C}$ - were the same, although $\mathrm{C}$ - consistently showed a somewhat higher final amount of growth than $\mathbf{C}+$. Sometimes this difference was significant, but not always. The average values are given in Table 8 . It may be definitely stated that $\mathrm{C}+$ utilizes glucose for growth no more efficiently than does $\mathbf{C}-$, although $\mathbf{C}+$ is capable of utilizing as sole carbon sources several important energy-yielding metabolites which $\mathrm{C}$ - cannot utilize.

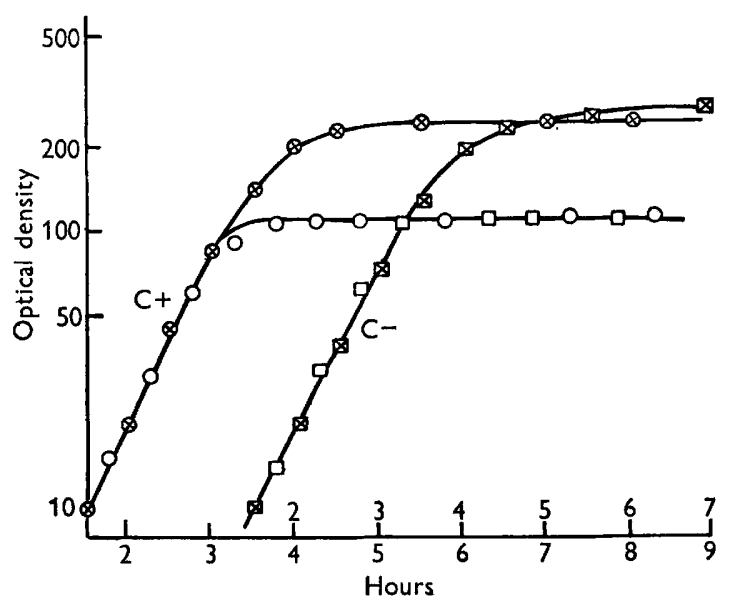

Fig. 5. Growth of $\mathbf{C}+$ and $\mathbf{C}-$ in aerated glucose cultures. $\mathbf{C}+$ in $0.05 \%(-\bigcirc-)$ and $0.5 \%$ $(-\otimes-)$ glucose; $\mathrm{C}-$ in $0.05 \%(-\square-)$ and $0.5 \%\left(-\otimes_{-}\right)$glucose. The $\mathrm{C}-$ growth curves are displaced $2 \mathrm{hr}$. to the right to permit comparison with $\mathrm{C}+$ curves.

Growth in cultures containing glucose and another carbon source. Glucosegrown populations of $\mathrm{C}+$ and of $\mathrm{C}$ - were inoculated in the usual way into media containing $0.05 \%$ glucose + one-half the standard concentration of citrate, succinate or acetate. The cultures were aerated and the growth was followed turbidimetrically. The results are shown in Fig. 1. The second growth period, corresponding to that in which citrate, succinate or acetate was being utilized by $\mathrm{C}+$, is completely lacking for $\mathrm{C}-$. This means that the $\mathrm{C}-$ mutant cannot utilize citrate, succinate or acetate even in cultures which contain a second utilizable carbon source.

Proof that the first growth period is the one in which glucose is utilized and that the second growth period is the one in which the second carbon source is utilized, is given by the results of the experiment illustrated in Fig. 2. In this experiment $\mathrm{C}+$ and $\mathrm{C}-$ were grown in media containing varying proportions of glucose and citrate $(0.05 \%$ glucose $+0.05 \%$ citrate or $0.025 \%$ glucose + $0.1 \%$ citrate). Comparison of $\mathrm{C}+$ controls, containing only glucose $(0.05$ or $0.025 \%$ ), with $\mathrm{C}+$ cultures containing both carbon sources, provides the conclusive evidence. It should be noted, furthermore, that the $\mathrm{C}$ - cultures containing the citrate supplement are no different from the $\mathrm{C}+$ controls containing only glucose. 


\section{Effect of aeration upon utilization of carbon sources}

The possibility existed that certain of the compounds (other than glucose), which were utilizable by $\mathrm{C}+$ and by $\mathrm{C}-$, could not be as efficiently utilized by $\mathrm{C}-$ as by the $\mathrm{C}+$ strain. To test this the following experiment was performed. The usual inocula from glucose cultures of $\mathrm{C}+$ and of $\mathrm{C}-$ were made into quadruplicate sets of media containing, respectively as sole carbon source, standard concentrations of glucose, pyruvate, malate, citrate or succinate. Two tubes of each medium were incubated with aeration and two without aeration. The final amounts and rates of growth were measured. Typical results are recorded in Table 8.

\section{Table 8. Effect of aeration upon the efficiency of utilization of various substrates by $\mathrm{C}+$ and by $\mathrm{C}-$ strains. of $\mathrm{A}$ aerogenes}

Tube cultures identically inoculated and containing the indicated compound as sole carbon source were either unaerated (standing cultures) or aerated on a roller device. Incubation was at $37^{\circ}$. Growth was measured turbidimetrically. Rates of growth in pyruvate media were not calculated because of insufficient growth in the visible range of turbidity.

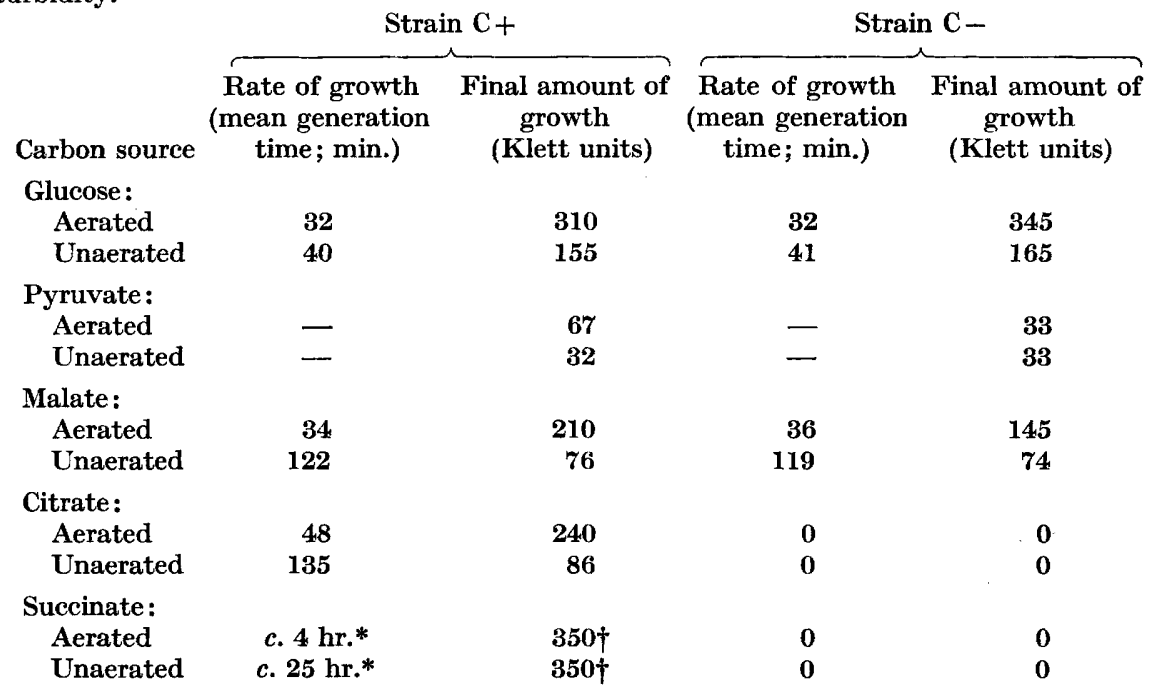

* The lag period prior to logarithmic rate of growth was $c .24 \mathrm{hr}$. in unaerated as compared to $c .48 \mathrm{hr}$. in aerated succinate medium.

$\dagger$ Final levels not accurately determined because of brown discoloration of succinate medium at growth levels greater than 350 Klett units.

The striking effect of aeration with any substrate was to increase the rate of growth. As with cultures growing on succinate, the increase in rate of growth by aeration could be observed even when the lag period was appreciably shorter in unaerated media. It was also clear that the $\mathrm{C}$ - strain could not utilize citrate or succinate whether or not the cultures were aerated. This finding was verified for each of the substrates that $\mathrm{C}-$ cannot utilize.

Aeration raised the final level of growth of the $\mathbf{C}+$ (wild-type) strain above 
that in unaerated media. This effect did not occur when $\mathrm{C}$ - was utilizing pyruvate; in this case the final amounts of growth were the same in aerated and in unaerated cultures. One other finding needs emphasis: the final amounts of growth that $\mathrm{C}+$ attained in aerated pyruvate and malate cultures were greater than those reached by $\mathrm{C}-$. In unaerated pyruvate and malate cultures, however, $\mathrm{C}+$ and $\mathrm{C}-$ reached the same final amount of growth. These experiments with pyruvate and malate were performed three times with results which were reproduced within the $5 \%$ experimental error observed in the measurements of any single experiment. It may be concluded, therefore, that aeration permits $\mathrm{C}+$ to utilize pyruvate and malate more efficiently than $\mathrm{C}-$. This greater efficiency is reflected neither in the rate of growth nor in the length of the lag phase, but in the final amount of growth. This fact renders unlikely any permeability differences between $\mathrm{C}+$ and $\mathrm{C}-$, since such differences would be expected to influence the lag period or rate of growth.

\section{Reversions of the $\mathrm{C}-$ mutant}

Endo reaction. All thirty-two independently isolated C - strains were alike with respect to the range of substrates which they utilized. In addition, all these strains were methyl-red negative, incapable of producing indole in tryptone broth (Difco), incapable of growing or producing indole in defined medium containing L-tryptophan as sole carbon source, and resistant to all the coli bacteriophages of the $\mathbf{T}$ series. In these respects, the $\mathrm{C}-$ strains of $\boldsymbol{A}$. aerogenes are exactly like the $\mathrm{C}+$ (wild-type) and unlike wild-type strains of $\boldsymbol{E s c h}$. coli. An interesting difference exists, however, in the growth characteristics of the $\mathrm{C}+$ and $\mathrm{C}-$ strains on Endo agar. When a light surface streak is made on Endo agar, no difference in the appearance of the growth of $\mathrm{C}+$ or $\mathrm{C}$ - can be noted during the first $12 \mathrm{hr}$. Both show a pinkish surface growth and only slight staining of the medium. This appearance is in sharp distinction to the dark red growth of Esch. coli on Endo agar, associated with an intense reddish purple staining of the medium. After $24 \mathrm{hr}$. (when Esch. coli growth and stain become extremely marked), the $\mathrm{C}+$ growth continues to increase, and although the growth becomes magenta red in colour, there is little change in the colour of the medium. The $\mathrm{C}-$ growth, on the other hand, ceases within $\mathbf{2 4} \mathrm{hr}$. and the medium gradually acquires a dark red colour which, however, never gets as intense as that due to Esch. coli. Thus, not only can a sharp distinction be made between the type of growth of Esch. coli and A. aerogenes on Endo agar, but a nice distinction can also be made between the 24 and $48 \mathrm{hr}$. surface streaks of $\mathrm{C}+$ and $\mathrm{C}-$ on this medium.

The difference in amounts of growth of $\mathrm{C}+$ and $\mathrm{C}-$ on Endo agar is probably explained by the fact that $\mathrm{C}+$ gives a greater final amount of growth on nutrient broth than does $\mathrm{C}-$; Endo agar contains a nutrient broth base. The greater accumulation in the $\mathrm{C}-$ cultures of an aldehydic substance which combines with the Schiff reagent (bisulphite-basic fuchsin) in Endo agar is noteworthy because it may throw some light on the nature of the metabolic block in the $\mathrm{C}$ - strains. 
Reversion pattern of $\mathrm{C}-$. Papillae isolated from the surface streaks of the C - strains on agar in the substrate-utilization tests were incubated on nutrient agar slopes and re-tested by streaking some of the growth on a number of single carbon source agars. Papillae recovered from $\mathrm{C}-$ streaks on citrate, $\alpha$-ketoglutarate and succinate agars fell into two classes: (1) those consisting of cells exactly like $\mathbf{C}+$ (wild-type) in the type of Endo reaction and in the range of substrates utilized; (2) those consisting of 'slow growers'. The latter were characterized by a long delay, slower growth, and occasionally not as heavy a growth as that of $\mathrm{C}+$ (wild-type) on the test agars. There was a good

\section{Table 9. Testing of papilla-isolates by surface agar streak method}

Slope cultures derived from papillae isolated in agar streak tests of mutant strains were re-tested by streaking across the surfaces of defined media solidified with washed agar and containing, respectively, the following compounds as sole carbon sources: glucose (G), citrate (C), $\alpha$-ketoglutarate ( $\alpha$-KG), glutamate (Glut), succinate (S), fumarate (F), aspartate (Asp). In Test I aspartate and glutamate were omitted. The $\mathrm{C}+$ (wild-type) control utilized all these compounds; the $\mathrm{C}$ - mutant control utilized only glucose.

$\begin{array}{ccccl}\begin{array}{c}\text { Mutant } \\ \text { strain tested }\end{array} & \begin{array}{c}\text { Papillae } \\ \text { isolated from } \\ \text { defined agar } \\ \text { containing }\end{array} & \begin{array}{c}\text { No. of } \\ \text { papillae } \\ \text { tested }\end{array} & \begin{array}{c}\text { Type of } \\ \text { Endo } \\ \text { reaction }\end{array} & \begin{array}{c}\text { Substrates } \\ \text { utilized by } \\ \text { papilla-isolates }\end{array} \\ \text { Test I: C- } & \text { F } & 15 & \text { C- } & \text { G, F } \\ & \text { F } & 1 & \text { C- } & \text { G; all others slow } \\ & \text { C } & 13 & \text { C- } & \text { G; all others slow } \\ & \text { C } & \mathbf{3} & \text { C+ } & \text { All } \\ & \alpha-\text { KG } & 12 & \text { C- } & \text { G; all others slow } \\ & \alpha-\text { KG } & 1 & \text { C+ } & \text { All } \\ \text { Test II: C- } & \text { S } & 14 & \text { C- } & \text { G; all others slow } \\ \text { Test III: } \text { C- F+ }+ & \text { S } & 1 & \text { C+ } & \text { All } \\ & \text { F } & 8 & \text { C- } & \text { G, F, Asp } \\ & \text { C } & 3 & \text { C+ } & \text { All } \\ & \text { C } & 1 & \text { C- } & \text { G; all others slow } \\ & \alpha-\text { KG } & 3 & \text { C+ } & \text { All } \\ & \text { S } & 1 & \text { C+ } & \text { All } \\ & \text { S } & 2 & \text { C- } & \text { G; all others slow } \\ & \text { Glut } & 1 & \text { C+ } & \text { All } \\ & \text { Glut } & 2 & \text { C- } & \text { G; all others slow }\end{array}$

correlation between the slow type of growth and the time of appearance of the papilla, the isolate of which showed that type of growth when tested. When a papilla appeared after the third or fourth day of incubation, it was always a 'slow grower' on test. There was also a correlation between 'slow growth' and the type of Endo reaction, for all 'slow growers' gave an Endo reaction like that of $\mathrm{C}-$. 'Slow growers' utilized all the substrates that $\mathrm{C}+$ (wild-type) could utilize, and were distinguishable from the latter only by the obvious difference in rate of growth and in type of Endo reaction.

Papillae recovered from $\mathrm{C}$ - streaks on fumarate agar also fell into two classes, one of which, however, consisted of cells which had regained ability to utilize fumarate and aspartate but none of the other compounds not 
utilized by $\mathrm{C}-$; the other class consisted of 'slow growers'. Papillae were never observed on acetate agar streaks. The reverted strains which were incapable of utilizing citrate but capable of utilizing fumarate $(\mathbf{C}-\mathbf{F}+$ ) possessed, like the 'slow growers' ( $\left.\mathrm{C}^{*}\right)$, a C - type of Endo reaction (Table 9).

The $\mathbf{C}-\mathbf{F}+$ reverted strains recovered from fumarate agar were then streaked in the usual way on citrate, $\alpha$-ketoglutarate, succinate and glutamate

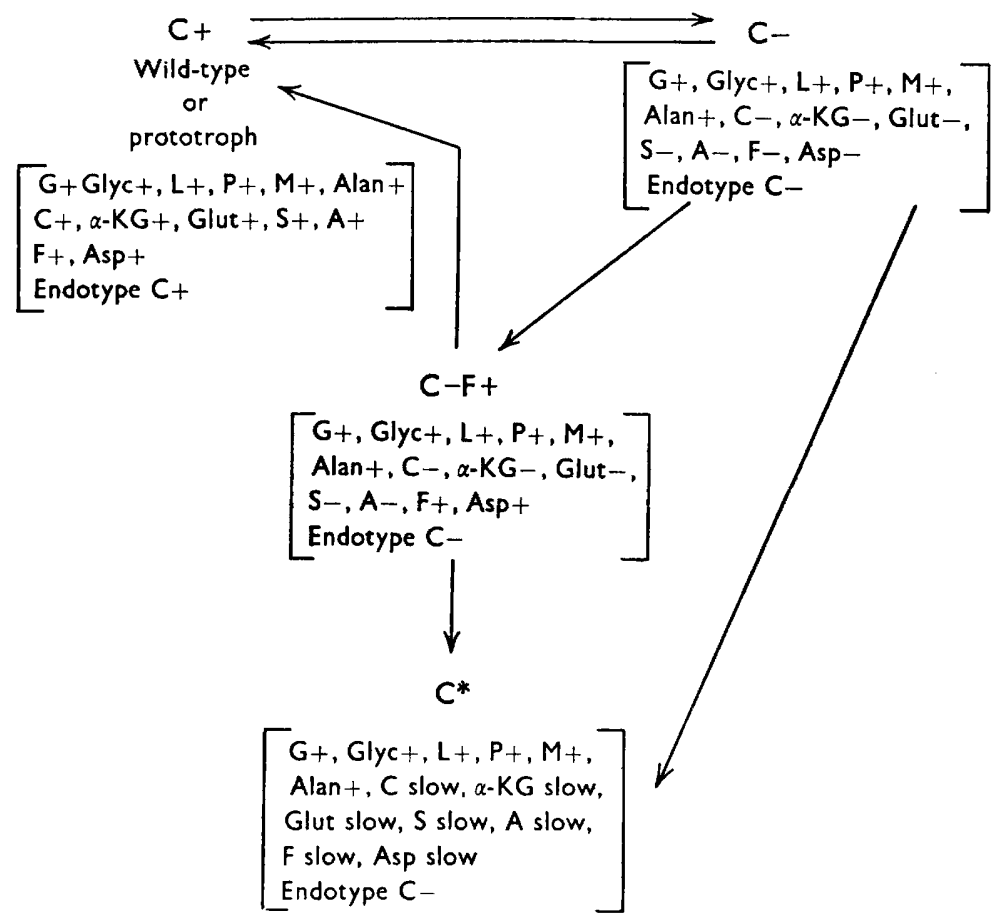

Fig. 6. Pattern of mutation and reversion in Aerobacter aerogenes with respect to the utilization of the Krebs cycle compounds. 'Endotype' refers to type of reaction shown by growth on Endo agar.

agars; papillae which appeared were isolated and tested. Two classes of isolates were again obtained: (1) prototrophic; (2) 'slow growers'. A summary of the papilla-testing procedure and some typical results are recorded in Table 9. From these results, it is possible to construct a scheme of the pattern of mutation and reversion in A. aerogenes strain 211, which is given in Fig. 6.

The various prototrophic and mutant types have been subjected to single colony isolation and maintained on nutrient agar slopes by serial transfer, and they have not lost their distinguishing characteristics. No physiological studies of the reverted strains comparable to those performed with the $\mathrm{C}-$ mutant have yet been made. Consequently, the $\mathrm{C}^{*}$ or slow-growing class has not been studied sufficiently to provide an understanding of the nature of the 'slow growth'. 


\section{DISCUSSION}

A certain class of carbon sources, which includes citrate, succinate, acetate, fumarate and $\alpha$-ketoglutarate, cannot be readily utilized by glucose-grown populations of $A$. aerogenes. This is reflected in a comparatively long lag period before the attainment of a logarithmic rate of growth by glucose-grown populations when inoculated into media containing one of these other substrates as the sole carbon source. The nature of this adaptive process is not yet understood, but the ensemble of the following facts makes it unlikely that we are dealing in this case with the selection of rare mutants in the glucosegrown populations :

(1) Every cell present in a log-phase glucose-grown population produces a colony when plated on a medium of washed agar + one of the aforementioned compounds as carbon source. Since log-phase glucose-grown $\mathrm{C}$ - mutant cells do not form colonies when plated on the same medium, no contaminating material in the agar appears to be available for the growth of cells incapable of utilizing the particular carbon source added to the medium.

(2) Eight generations of growth in glucose medium are enough to require that a population derived from cells that were originally adapted to one of the aforementioned compounds should re-adapt to this compound. This indicates that adapted cells are not mutants which inherit ability to utilize the compound in question, but rather are transitorily, physiologically altered, cells.

The present case, therefore, seems to be one of physiological adaptation by the individual cells exposed to succinate, or acetate, etc., after being previously grown on glucose. The results obtained in this investigation have shown that this adaptive process is susceptible to two kinds of obstruction. One is nongenetic; that is, it is not inherited by the cells in which the obstruction occurs. When one of these cells is inoculated into a medium in which it can divide, the obstruction disappears and the cell is once more capable of adaptive growth. The other obstruction is stable, for a cell in which it occurs gives rise to progeny that do not regain the lost adaptive ability.

Adaptation involves the setting into action of a complex of biochemical reactions, and these, according to Monod (1950), must at some point require the intervention of the genetic apparatus of the cell. In wild-type cells the usual effect of mutation is to prevent, in some way, this complex of reactions from occurring. The nature of the reactions blocked in the $\mathrm{C}-$ mutant of $A$. aerogenes cannot be determined from the results so far obtained. It seems likely, however, that at least one of these reactions is an aeration-dependent reaction in the dissimilation of pyruvate, since the growth of $\mathrm{C}+$ and of $\mathrm{C}-$ on pyruvate is identical except when aerated. The results also justify the assumption that the reactions blocked in the mutant do not occur in wild-type $A$. aerogenes when growing on glucose, for such an assumption will account at once for two of the present findings; namely, that the growth of $\mathrm{C}-$ in glucose cultures is the same as that of $\mathrm{C}+$; and that the class of compounds which $\mathrm{C}-$ cannot utilize coincides exactly with the class of compounds to which the $\mathbf{C}+$ 
strain slowly adapts after growth on glucose. The reactions that are slowly set in action in wild-type cells which are inoculated into media containing citrate or succinate, etc., after having previously grown on glucose, are probably the ones that are completely blocked in the $\mathrm{C}-$ mutant. The question arises whether these reactions, genetically blocked in the $\mathrm{C}-$ mutant and not occurring in wild-type cells during their growth on glucose, include reactions in the Krebs cycle. One may conclude that either the Krebs cycle does not operate during glucose dissimilation or that the utilization of exogenous citrate, succinate, acetate, etc., by cells previously grown on glucose requires at the outset certain reactions that bring these substrates into the Krebs cycle. It is conceivable, for example, that these substrates must be coupled to a specific compound in order to be metabolized via the Krebs cycle, and that the coupling reactions are the ones blocked in the mutant and involved in adaptation.

That the substrates involved in the non-genetic effect correspond to the substrates not utilizable by the $\mathrm{C}$ - mutant suggests some close relationship between the non-genetic effect and the mutation. In this connexion, it is significant that the kinetics of the induction of the non-genetically modified cells can be interpreted on the basis of the inactivation of 1 or 2 particles/cell (Ravin \& Norman, 1952). Finally, the fact that ultraviolet radiation can induce the non-genetic effect (Ravin \& Norman, 1952) suggests that material containing nucleic acid may be the site of this action.

The mutation from $\mathrm{C}+$ to $\mathrm{C}-$ in $A$. aerogenes is of taxonomic interest because it affects a character that is used to distinguish this species from Esch. coli. Whatever may be the nature of the block engendered by this mutation, it is undoubtedly not the same as that which prevents the utilization of citrate in Esch. coli, because a comparison of the substrates utilized by $\mathrm{C}+$ and $\mathrm{C}-$ strains in both species (A. aerogenes 211 and Esch. coli $\mathrm{T} 16)$ reveals that, whereas in Esch. coli only the utilization of citrate is affected by mutation, in $A$. aerogenes the utilization of a wide variety of other ' $K$ rebs cycle compounds' is also affected. Nevertheless, the step-wise regaining of ability to utilize some of these other compounds, as illustrated by the $\mathbf{C}-\mathbf{F}+$ reversion, indicates how, in the course of evolution of an originally $\mathrm{C}+A$. aerogenes strain, a condition could be attained approximating that of $E s c h$. coli with respect to the utilization of 'Krebs cycle compounds'. In any case, the existence of mutations affecting characters that are used to distinguish between species supports the view that among bacteria, as well as among higher organisms, mutations serve as the raw materials for biochemical evolution.

I wish to express my gratitude to: the National Cancer Institute of the United States Public Health Service for a Pre-Doctoral Fellowship awarded me in 1949-50; the United States Public Law 346, by the provisions of which financial support was obtained at an earlier period; Prof. F. J. Ryan for his interest, encouragement and criticism; Dr K. C. Atwood for much fruitful advice. 


\section{REFERENCES}

AJL, S. J. (1950). Acetic acid oxidation by $E$. coli and A. aerogenes. J. Bact. 59, 499.

Aubel, E., Rosenbehg, J. \& Szulmajster, J. (1950). Contribution à l'étude de la fermentation et de la respiration de $\boldsymbol{E}$. coli. I. Action de quelques inhibiteurs sur la respiration et la fermentation de E. coli. Biochem. Biophys. Acta, 5, 228.

Baskett, A. C. \& Hinshelwood, C. (1949). The utilization of carbon sources by B. lactis aerogenes. I. General survey. Proc. Roy. Soc. B, 136, 520.

Bergey's Manual of Determinative Bacteriology (1948). 6th ed. edited by Breed, R. S., Murray, E. G. D. \& Hitchens, A. P. Baltimore: Williams \& Wilkins Co.

Buffa, P., Coxon, R. V., Liébecq, C. \& Peters, R. A. (1949). Experiments on the Tricarboxylic Acid Cycle in Brain and Kidney Tissues, p. 570. Trans. first int. Congr. Biochem.

Chain, E. \& Duthie, E. S. (1945). Bactericidal and bacteriolytic action of penicillin on the staphylococcus. Lancet, i, 652.

Dagley, S., Dawes, E. A. \& Morrison, G. A. (1949). Influence of amino-acids and compounds in the Krebs oxidation cycle, on 'early lag'. Biochem. J. 45, xxvi.

Dagley, S., Dawes, E. A. \& Morrison, G. A. (1951). The effect of aeration on the growth of Aerobacter aerogenes, with reference to the Pasteur mechanism. J. Bact. $61,433$.

Davis, B. (1948). The isolation of biochemically-deficient mutants of bacteria by penicillin. J. Amer. chem. Soc. 70, 4267.

Hobby, G. L., Meyer, K. \& Chaffee, E. (1942). Observations on the mechanism of penicillin. Proc. Soc. exp. Biol., N.Y. 50, 281.

LeDERBERG, J. \& Zinder, N. (1948). Concentration of biochemical mutants of bacteria with penicillin. J. Amer. chem. Soc. 70, 4267.

Lentr, C. (1946). Oxidation of pyruvic acid by B. coli communis. Boll. Soc. ital. Biol. sper. 22, 332.

Monod, J. (1942). Recherches sur la croissance des cultures bacteriennes. Paris: Hermann et Cie.

Monod, J. (1950). Adaptation, Mutation and Segregation in the Formation of Bacterial Enzymes. Biochemical Symposia No. 4 (edited by R. T. Williams). Cambridge University Press.

Nelson, T. C. (1949). Adaptation of $E$. coli to the use of four carbon dicarboxylic acids. Anat. Rec. 105, 94.

Novelui, G. D. \& LipmanN, F. (1950). The catalytic function of coenzyme $A$ in citric acid synthesis. J. biol. Chem. 182, 213.

PARr, L. W. (1938). A new mutation in the coliform group of bacteria. J. Hered. 29, 381.

Ravin, A. W. \& Norman, A. (1952). Studies on a non-heritable physiological modification in $A$. aerogenes. Experientia (in the Press).

Ryan, F. J. (1950). Selected methods of Neurospora research. In Methods in Medical Research, Vol. 3. Chicago: The Year Book Publishers Inc.

(Received 31 July 1951) 